\title{
Analysis of risk factors for adjacent superior vertebral pedicle-induced facet joint violation during the minimally invasive surgery transforaminal lumbar interbody fusion: a retrospective study
}

\author{
Zhi-Li Zeng ${ }^{\dagger}$, Long Jia ${ }^{\dagger}$, Wei Xu', Yan Yu, Xiao Hu, Yong-Wei Jia, Jian-Jie Wang and Li-Ming Cheng ${ }^{*}$
}

\begin{abstract}
Background: The purpose was to explore possible risk factors of facet joint violation induced by adjacent superior vertebral pedicle screw during the minimally invasive surgery transforaminal lumbar interbody fusion (MIS-TLIF).

Methods: A total of 69 patients with lumbar degenerative disease, who underwent MIS-TLIF were retrospectively reviewed. Postoperative computed tomography images were used to assess the facet joint violation. The correlation of facet joint violations with gender, age, body mass index (BMI), the adjacent superior vertebral level, fusion segment numbers, position of screw insertion, straight leg-raising test (SLRT) results, clinical diseases and renal dysfunction were analyzed by Chi-square tests and binary logistic regression analysis.

Results: The incidence of adjacent superior facet joint violations was $25.4 \%$. Chi-square test showed the patients with age $<60$ and high BMI $\left(\geq 30 \mathrm{~kg} / \mathrm{m}^{2}\right)$ were more prone to have facet joint violations $(P=0.007 ; P=0.006)$. The single segment fusion presented more facet joint violations than the double segments fusion $(P=0.048)$. The vertebral pedicle screw implant location at $L 5$ showed more facet joint violations compared with that at $L 3$ and $L 4(P=0.035)$. No correlation was found between gender, screw implant position, SLRT results, clinical diseases and renal dysfunction and facet joint violations. Logistic regression analysis revealed that age $<60$ years (OR: 2.902; $95 \% \mathrm{Cl} 1.227-6.864$; $P=0.015)$ and $\mathrm{BMI} \geq 30 \mathrm{~kg} / \mathrm{m}^{2}$ (OR: $2.825 ; 95 \% \mathrm{Cl} 1.191-6.700 ; P=0.018<0.05$ ) were significantly associated with facet joint violation.
\end{abstract}

Conclusion: These results found a high incidence of adjacent superior vertebral facet joint violation in the MIS-TLIF. Age $<60$ and $\mathrm{BMI} \geq 30 \mathrm{~kg} / \mathrm{m}^{2}$ might be risk factors of facet joint violation.

Evidence level: Level 4.

Keywords: MIS-TLIF, Facet joint violation, Pedicle screw, Risk factor

\section{Background}

Transforaminal lumbar interbody fusion (TLIF) is prevalent in the management of some spinal disorders that require lumbar fusion $[1,2]$. Recently, with development

\footnotetext{
*Correspondence: chlm.d@163.com

${ }^{\dagger} Z$ Zhi-li Zeng, Long Jia, and Wei Xu are the co-first authors

Department of Spine Surgery, Tongji Hospital, Tongji University School of Medicine, 389 Xincun Road, Shanghai, China
}

of minimally invasive concept and medical instruments, minimally invasive surgery transforaminal lumbar interbody fusion (MIS-TLIF) has been increasingly accepted due to its advantages in less intraoperative blood loss, weaker intensity of postoperative pain, and shorter hospitalization [3-5].

Recently, increasing concern has been given on the postoperative complications. The most common 
long-term complication is adjacent segment degeneration. There is evidence that sagittal orientation or tropism at the adjacent segment might be potential risk factors of adjacent segment degeneration [6]. Altered Sagittal balance $[7,8]$ and deperiostation [9] also contribute to more degeneration of adjacent segment. Biochemical analysis reveals that the lumbar fusion causes increased facet loading that might lead to adjacent segment degeneration $[10,11]$. Moreover, it has been established that the adjacent vertebral facet joint violation is a potential risk factor for accelerating the adjacent segment degeneration [12, 13]. Furthermore, one main contributor to the facet joint violations is placement of the pedicle screws $[13,14]$.

In MIS-TLIF, pedicle screws are inserted percutaneously without direct visualization of the facet joint, and suspected to be responsible for increased facet joint violations and long-term risk of adjacent segment degeneration [15-17]. To date, several studies have compared open and percutaneous pedicle screw placement and explored the risk factors of facet violation. For instance, it has been revealed that minimally invasive pedicle screw placement does not result in increased facet violation compared with open surgery, and higher BMI is a potential contributor to increased facet violation [18]. However, another study argues that percutaneous pedicle screw placement is associated with higher incidences of high-grade facet joint violation relative to open surgery, and several potential risk factors of facet violation are identified, such as age $<65$, pedicle screw placement at L4 and obesity [19]. Regardless of these controversial viewpoints, exploring the risk factors that contribute to the facet joint violations in MIS-TLIF is very imperative. There are few studies investigating the risk factors of facet joint violations specifically in patients undergoing MIS-TLIF. Therefore, in this study, we retrospectively reviewed the clinical data of 69 patients who underwent MIS-TLIF, and assessed relevant risk factors of facet joint violation caused by adjacent superior vertebral pedicle screw, including gender, age, BMI, the location of adjacent upper vertebral, fusion segment numbers, screw implant location and others.

\section{Methods}

\section{The patients}

From December, 2012 to June, 2014, 95 consecutive patients with lumbar degenerative disease (male, 35; female, 34; average age: $54.8 \pm 4.8$ years) who underwent minimally invasive surgery transforaminal lumbar interbody fusion (MIS-TLIF) were retrospectively reviewed in this study (approved by Tongji Hospital, Tongji University School of Medicine). The surgical indications were patients who had clear lumbocrural pain or fall bilge feeling and invalid improvements after at least 3 months of conservative treatment. Of the 95 patients, 73 patients met the inclusion criteria: patients suffered from lumbar degenerative disease with lumbar disc herniation or lumbar spinal stenosis or lumbar spondylolisthesis or endplate Modic changes [20]. These diseases were confirmed by preoperative computed tomography $(\mathrm{CT})$ and magnetic resonance imaging (MRI). The exclusion criteria were as follows: presence of obvious pedicle screw position deviation or even needing a second revision surgery because of non-standard surgical manipulation; degenerative lumbar scoliosis; spinal tumor. Then, 4 patients were excluded. Finally, 69 patients were included in the study with complete medical records and follow-up data (Fig. 1). Among the patients, 45 patients were with hip or unilateral lower limb radiation pain, 20 patients were with bilateral lower limb radiation pain, 25 patients were with positive results of straight leg-raising test (SLRT) and strengthen test, and 3 patients were with urine dysfunction.

Preoperative CT and MRI examination showed obvious lumbar disc herniation and (or) lumbar spinal stenosis in 48 cases, lumbar spondylolisthesis in 9 cases and endplate Modic changes in 12 cases. The study protocol was approved by local ethics committee. Informed consent was obtained from each patient prior to the study. The operation was performed by two deputy or chief surgeons who had more than 15-year experience in orthopedic surgery. There were 62 cases with single segment fusion and 7 cases with double segments fusion. The position of adjacent superior vertebral pedicle screw insertion in these cases was detailed as follows: L3, 4

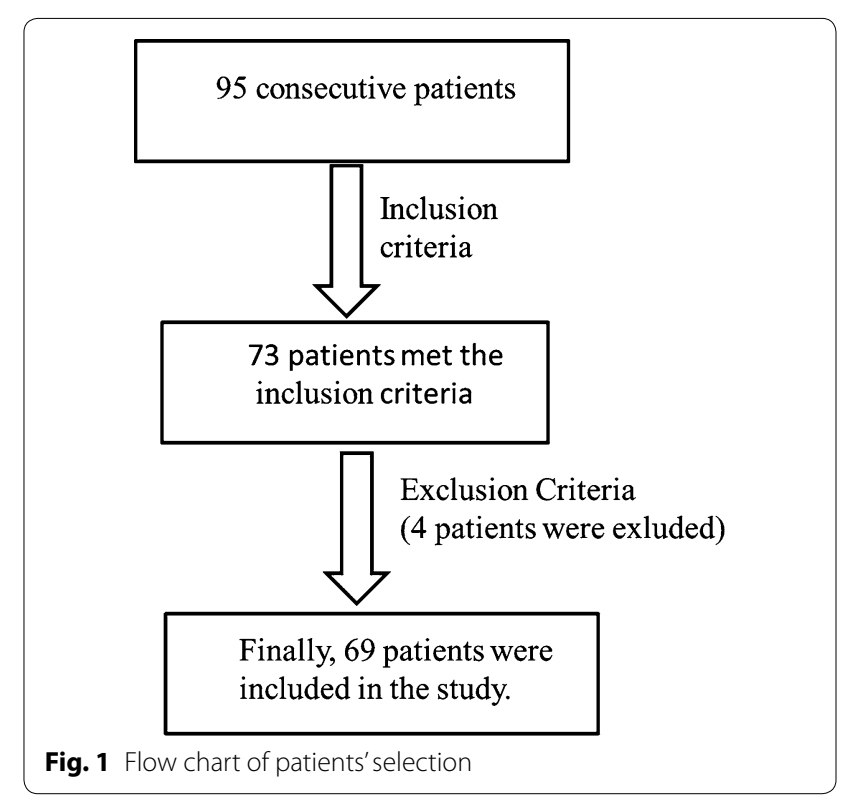


cases; L4, 45 cases; L5, 20 cases. In addition, 69 pedicle screws were placed on the left and the right side of the spine of the patients, respectively.

\section{Surgical technique}

Patients were kept in prone position following general anesthesia and their abdomen was suspended and pressure parts were with pad. C arm fluoroscopy was used to determine available surgical space. A 2- to $3-\mathrm{cm}$ incision was made approximately $2.5 \mathrm{~cm}$ lateral to the midline to cut skin and muscular fasciae. After inserting the dilators step by step, Pipeline working channel (Johnson \& Johnson Company, NY, USA, Fig. 1) was placed into and fixed by dilators, or directly using Spotlight working channel (Johnson \& Johnson Company, NY, USA, Fig. 2). Then, the local soft tissue was removed to expose vertebral plate edges and facet joint. The decompression was performed to expose dural sac, the central canal, lateral crypt and nerve root canal after removing part of vertebral plate, ligamentum flavum and facet joints. After thoroughly removing intervertebral disc and cartilage endplate, local autologous bone was implanted into intervertebral space, and then single suitable height of intervertebral fusion was placed. For bilateral decompression or more, the same method was performed to deal with the contralateral and other spaces. Under the guidance of $\mathrm{C}$ arm fluoroscopy, placement of percutaneous pedicle screws was performed using Viper2 system (Johnson \& Johnson Company, NY, USA, Fig. 1) and percutaneous rod was also placed using the instruments and pre-locked. Drainage tube was removed 24-36 h postoperatively. At 3 days postoperatively, the patients were examined with lumbar X-ray and CT to confirm the position of lumbar fusion instruments and internal fixation, and to evaluate the facet joint violation. Moreover, the patients were encouraged to have activities out of bed under waist protection. Waist torsion and bending activities were prohibited within 3 months under waist protection.

\section{Radiographic evaluation and observation index}

All the patients were examined postoperatively by lumbar spinal 64-row CT thin layer scanning with $0.5 \mathrm{~mm}$ slices. The CT images were assessed by Picture Archiving and Communication Systems. The evaluation standard was according to Seo taxonomy which developed a point system to evaluate the facet joint violations on patients' CT scan. Specifically, no points were given when the vertebral pedicle screw clearly avoided the facet joint; one point was given when the vertebral pedicle screw head was either in contact with or suspected to have invaded the facet joint; two points were given when the screw had clearly invaded the facet joint (Fig. 3) [21]. The facet violation grade was assessed independently by two surgeons who were blinded to the clinical diseases of patients. If their results are different, the senior author determined the facet violation grade finally. The inter-observer reliability was calculated according to the kappa statistics (kappa coefficient $=0.65)$. In addition, X-ray examination was also performed to study the facet violation of the patients operatively.

\section{Statistics analysis}

All analyses were conducted using SPSS software, version 17.0. Gender, age, BMI, adjacent superior vertebral level, fusion segment numbers, screw implant location, SLRT results, clinical diseases and renal dysfunction were compared between patient with or without facet joint violations using Chi-square tests. Binary logistic regression analysis was performed to identify significant risk factors of facet joint violation. $P<0.05$ was considered to be significant.

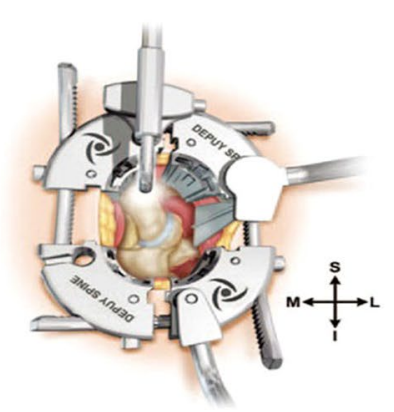

Pipeline System

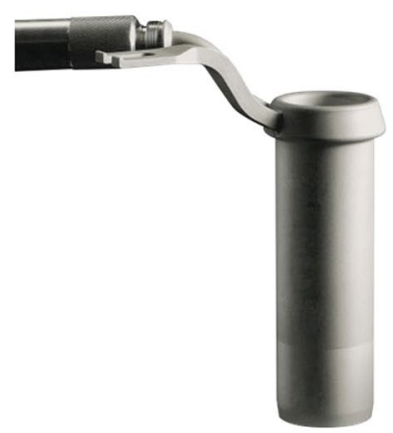

Spotlight System

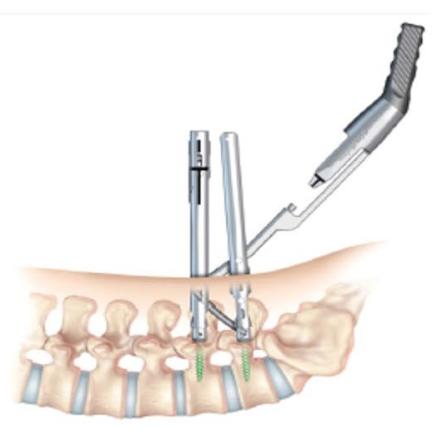

Viper 2 System

Fig. 2 The instrument used in the procedure of MIS-TLIF 


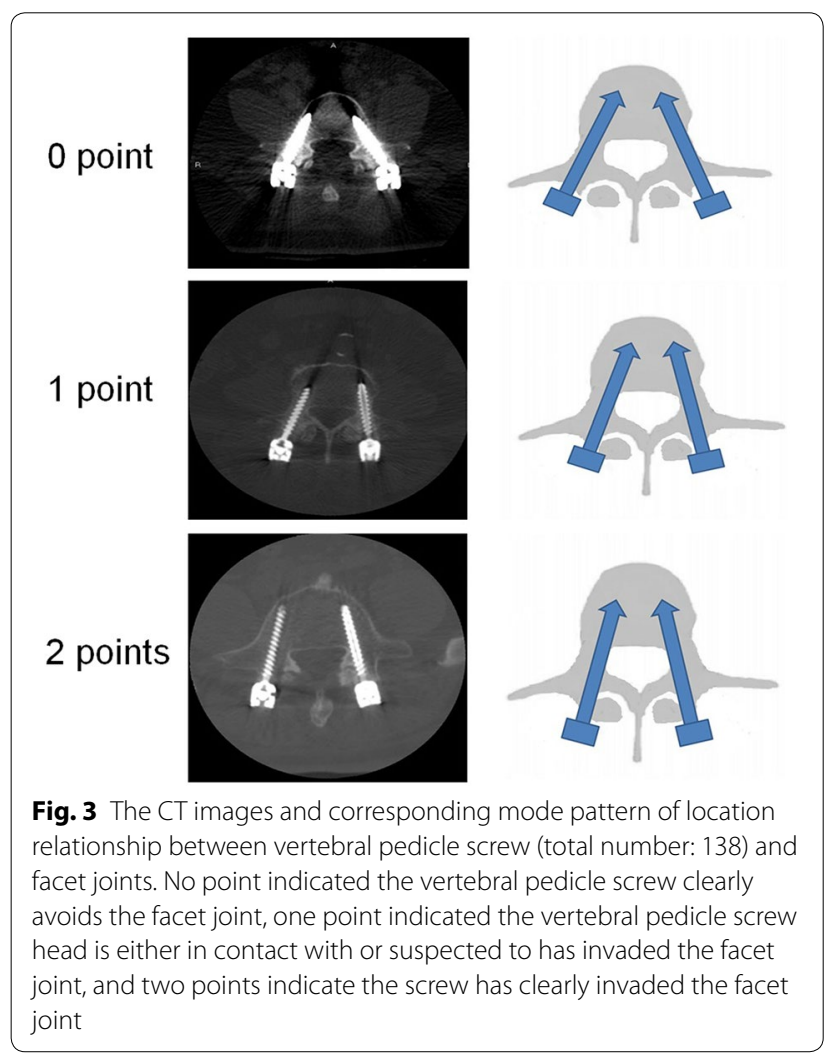

\section{Results}

The 69 patients successfully underwent the MIS-TLIF. The postoperative CT scans showed the location relationship between vertebral pedicle screw (total number: $138)$ and facet joint: no point, $74.6 \%(n=103)$; one point, $16.0 \%(n=22)$; two points $(n=13), 9.4 \%$. It showed that the incidence of facet joint violations ( $\geq$ one point) was $25.4 \%$ in these patients. The exemplary X-ray images for no point, one point and two points were exhibited in Fig. 4.

Chi-square test revealed that (Table 1) the patients who were $<60$ years old, with high BMI $\left(\geq 30 \mathrm{~kg} / \mathrm{m}^{2}\right)$ were more prone to have facet joint violations $(P=0.007$; $P=0.006)$. The single segment fusion presented more facet joint violations than the double segments fusion $(P=0.048)$. The pedicle screw implant at L5 showed more facet joint violations compared with those at L3 and L4 $(P=0.035)$. However, the difference of gender, screw implant location, results of SLRT, clinical diseases and renal dysfunction was not significant between the patients with facet joint violations ( 1 and 2 points) and the patients without facet joint violation ( 0 point) $(P=0.493 ; P=0.328 ; P=0.177 ; P=0.942 ; P=0.983)$.

Logistic regression analysis was further performed to determine whether age $<60$ years old, BMI $\geq 30 \mathrm{~kg} /$ $\mathrm{m}^{2}$, single segment fusion and pedicle screw implant

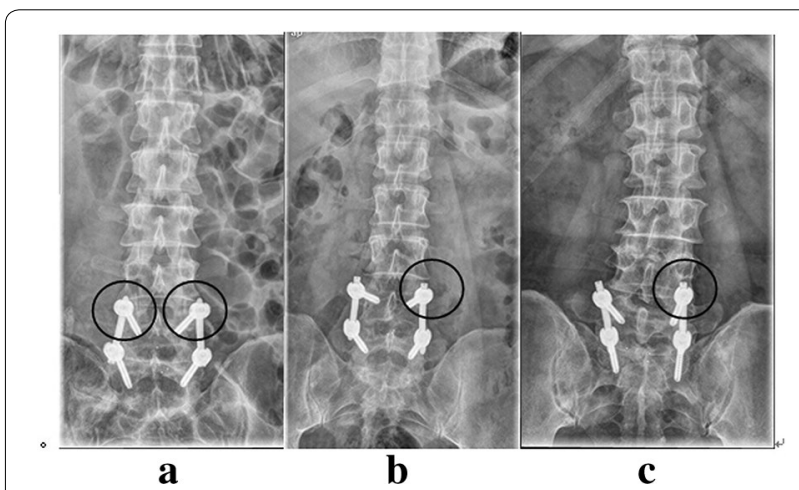

Fig. 4 Postoperative $X$-ray images of patients. a X-ray image of 0 point facet joint violation; $\mathbf{b} X$-ray image of one point facet joint violation; c X-ray image of two point facet joint violation

at L5 were risk factors of facet joint violation. Table 2 shows that relative to patients $\geq 60$ years old, patients younger than 60 years old have 2.902 increased odds of experiencing facet joint violation (95\% CI 1.227-6.864; $P=0.015<0.05$ ). Besides, patients with BMI $\geq 30 \mathrm{~kg} / \mathrm{m}^{2}$ has 2.825 increased odds of experiencing facet joint violation $(95 \%$ CI 1.191-6.700; $P=0.018<0.05)$ compared to patients with BMI $<30 \mathrm{~kg} / \mathrm{m}^{2}$. Single segment fusion and pedicle screw implant at L5 were not significantly associated with facet joint violation $(P=0.998 ; P=0.071)$.

\section{Discussion}

The current study investigated the risk factors of facet joint violations in patients undergoing MIS-TLIF. The results indicated that the incidence of facet joint violations was $25.4 \%$. Moreover, the study found that age $<60$ years and high BMI $\left(\geq 30 \mathrm{~kg} / \mathrm{m}^{2}\right)$ were suggested to be independent risk factors for facet joint violations. Gender, vertebral level, fusion segment numbers, screw implant location, result of SLRT, clinical diseases and renal dysfunction were not significantly associated with facet joint violations.

Facet joint is an important structure to maintain the stability of lumbar spine motion segments. The paired facet joint with lumbar intervertebral disc constitute the lumbar complex which is responsible for the spine movement, stability, torsion and load-bearing ability [22]. Facet joint violations can destruct the spine stability and further accelerate the development of adjacent segment degeneration [23]. Park et al. [14] have found that compared with other forms of instrumentation or with no instrumentation, transpedicular instrumentation is prone to cause symptomatic adjacent segment disease, and that the possible risk is the adjacent facet joint violations during the pedicle screw placement. Moreover, a cadaveric study also indicates that the complications are 
Table 1 Comparison of gender, age, body mass index (BMI), vertebral level, fusion segment numbers, screw implant location, result of straight leg-raising test, clinical diseases and renal dysfunction between patient with or without facet joint violations

\begin{tabular}{|c|c|c|c|c|}
\hline \multirow[t]{2}{*}{ Factors } & \multirow[t]{2}{*}{$\begin{array}{l}\text { Screw } \\
(n)\end{array}$} & \multicolumn{2}{|c|}{$\begin{array}{l}\text { Location relation- } \\
\text { ship between ver- } \\
\text { tebral pedicle screw } \\
\text { and facet joint }(n)\end{array}$} & \multirow[t]{2}{*}{$P$ value } \\
\hline & & 0 Point & $1+2$ Point & \\
\hline Gender & & & & 0.493 \\
\hline Male & 70 & 54 & $16(11+5)$ & \\
\hline Female & 68 & 49 & $1(11+8)$ & \\
\hline Age & & & & $0.007^{*}$ \\
\hline$<60$ & 82 & 68 & $14(10+4)$ & \\
\hline$\geq 60$ & 56 & 35 & $21(12+9)$ & \\
\hline BMl & & & & $0.006^{*}$ \\
\hline$<30 \mathrm{~kg} / \mathrm{m}^{2}$ & 86 & 71 & $15(10+5)$ & \\
\hline$\geq 30 \mathrm{~kg} / \mathrm{m}^{2}$ & 52 & 32 & $20(12+8)$ & \\
\hline $\begin{array}{l}\text { Adjacent superior vertebral } \\
\text { level }\end{array}$ & & & & $0.035^{*}$ \\
\hline L3 & 8 & 8 & 0 & \\
\hline$\llcorner 4$ & 90 & 69 & $21(13+8)$ & \\
\hline L5 & 40 & 26 & $14(9+5)$ & \\
\hline Fusion segment & & & & $0.048^{*}$ \\
\hline Single & 124 & 89 & $35(22+13)$ & \\
\hline Double & 14 & 14 & 0 & \\
\hline Implant location & & & & 0.328 \\
\hline Left & 69 & 49 & $20(13+7)$ & \\
\hline Right & 69 & 54 & $15(9+6)$ & \\
\hline Straight leg-raising test & & & & 0.177 \\
\hline Negative result & 88 & 69 & $19(12+6)$ & \\
\hline Positive result & 50 & 33 & $17(10+7)$ & \\
\hline Clinical diseases & & & & 0.942 \\
\hline $\begin{array}{l}\text { Lumbar disc herniation } \\
\text { and spinal stenosis }\end{array}$ & 96 & 71 & $25(14+11)$ & \\
\hline Lumbar spondylolisthesis & 24 & 18 & $6(4+2)$ & \\
\hline Endplate Modic changes & 18 & 14 & $4(3+0)$ & \\
\hline Renal dysfunction & & & & 0.983 \\
\hline No & 132 & 98 & $34(22+12)$ & \\
\hline Yes & 6 & 5 & $1(0+1)$ & \\
\hline
\end{tabular}

Table 2 Result of logistic regression analysis

\begin{tabular}{llll}
\hline & OR & $\mathbf{9 5} \% \mathbf{C l}$ & P value \\
\hline Age $>60$ years old & 2.902 & $1.227-6.864$ & 0.015 \\
$\mathrm{BMI}>30 \mathrm{~kg} / \mathrm{m}^{2}$ & 2.825 & $1.191-6.700$ & 0.018 \\
Single segment fusion & 0.000 & 0.000 & 0.998 \\
Pedicle screw implant at L5 & 2.177 & $0.935-5.071$ & 0.071 \\
\hline
\end{tabular}

$O R$ odd ratio, $\mathrm{Cl}$ confidence interval more serious when the superior facet joints were violated by the placement of pedicle screw [24]. Therefore, in this study, the results showed that the rate of facet joint violations with percutaneous pedicle screw insertion was $25.4 \%$, which was not consistent with the previous studies in which the incidence of facet joint violation displays wide variation and ranges from 3.2 to $50 \%[19,25,26]$. One possible contributor to the inconsistent results is the varied definition and assessment methods of facet joint violations in different studies. Moreover, the sample was relatively small in this study which might be another reason responsible for the inconsistent results.

Previously, several studies have investigated the potential risk factors for the joint violations. A retrospective study performed by Ranjith Babu et al. has demonstrated that patients' age $<65$ and obesity contribute to the increased difficulty in avoiding the facet joint violations [19]. BMI $>29.9$ is a potential contributor to increased facet violation [18]. Similarly, in the present study, the logistic regression analysis found that patients younger than 60 years old, with $\mathrm{BMI} \geq 30 \mathrm{~kg} / \mathrm{m}^{2}$ were independent risk factors of facet joint violations in the MISTLIF. The greater skin elasticity and stronger muscle of younger patients may make it more difficult to get the tactile sensation of the facet and to achieve an appropriate entry site. Moreover, it has been reported that clear radiological intraoperative images are not easy to be observed from the obese patients [16, 27], and that the hypertrophic tissue in obese patients increases the distance from the skin to the spine. The above factors make it more difficult to achieve an ideal entry site with appropriate angulation and further decrease the accuracy of percutaneous pedicle screws placement. However, Park et al. [15] have found no significant relationships between patients' age, BMI and the incidence of facet joint violations. These controversies are needed to be further investigated.

In addition, facet joint violations caused by the placement of pedicle screw are more frequent at the L4, L5 pedicel level than at the L3. The results from Park et al's research indicate that violations occur more frequently at the cranial pedicle screws of L5 pedicle than at other pedicels [15]. In the current study, the Chi-square test results also indicated that the incidence of facet joint violations at L5 pedicle was significantly higher than that at the L3 and L4 pedicel levels. The possible explanation is that the facet joint and the caudal portions of the laminae are more toward the frontal plane at L5-S1 level than other levels, which may increase the difficulty of percutaneous screws placement [28]. Moreover, the increased lordosis and paravertebral muscles at the L5-S1 level may 
also contribute to the increased facet joint violation [29]. Besides, a retrospective study of Moshirfa et al. indicates that a higher incidence of superior-level facet joint violation is observed in single-level fusion compared with that in multiple-level fusion [30]. However, Park et al. [15] have found no correlation between the number of fused segment and facet joint violation. In this study, the Chi-square test also found the single segment fusion was more prone to experience facet joint violation than the double segments fusion. The pedicle screws insertion with single segment fusion in this study was mostly at L5 level where the facet joint violation was more difficult to avoid. It seemed to provide a rational explanation for the results of this study. However, the logistic regression analysis revealed that single segment fusion and pedicle screws insertion at L5 were not significantly associated with the facet joint violation. Further studies of large sample size were needed to validate the results. Meanwhile, Moshirfa et al. [30] found that the screw implant at the left side was prone to cause facet joint violation. Conversely, the present results indicated no significant difference of facet joint violation between the screw placement at the left side and at the right side (left vs. right), which might be attributed to the assistance of $\mathrm{C}$ arm fluoroscopy. These controversies and assumption are worthy to be further investigated.

The study is presented with several limitations. First, the sample size of the study was small. Therefore, larger and multiple-center studies are needed in future study to confirm the results. Second, due to the limited duration of follow-up, the correlation between adjacent superior pedicle facet joint violation and late clinical outcome was incapable to be investigated, which will be a focus in the future study. In addition, the association between preoperative lumbar degeneration and facet joint violation was also an intriguing research direction.

\section{Conclusion}

The results from this retrospective study found a high incidence of adjacent superior vertebral facet joint violation in the MIS-TLIF. Age $<60$ years old and BMI $\geq 30 \mathrm{~kg} /$ $\mathrm{m}^{2}$ were independent risk factors of facet joint violation.

\section{Authors' contributions \\ ZLZ and LJ participated in the design of this study, and they both performed the statistical analysis. WX, YY and XH carried out the study and collected important background information. YWJ, JJW and LMC drafted the manu- script. All authors read and approved the final manuscript.}

\section{Acknowledgements}

This study was supported by Research Funding from Shanghai Hospital Development Center (SHDC-12013108).

Compliance with ethical guidelines

\section{Competing interests}

The authors declare that they have no competing interests.
Received: 18 June 2015 Accepted: 14 September 2015

Published online: 24 September 2015

\section{References}

1. Lowe TG, Tahernia AD, O'Brien MF, Smith DA. Unilateral transforaminal posterior lumbar interbody fusion (TLIF): indications, technique, and 2-year results. J Spinal Disord Tech. 2002;15(1):31-8.

2. Moskowitz A. Transforaminal lumbar interbody fusion. Orthop Clin North Am. 2002;33(2):359-66.

3. Foley K, Lefkowitz M. Advances in minimally invasive spine surgery. Clin Neurosurg. 2001;49:499-517.

4. Schwender JD, Holly LT, Rouben DP, Foley KT. Minimally invasive transforaminal lumbar interbody fusion (TLIF): technical feasibility and initial results. J Spinal Disord Tech. 2005;18:S1-6.

5. Lee KH, Yue WM, Yeo W, Soeharno H, Tan SB. Clinical and radiological outcomes of open versus minimally invasive transforaminal lumbar interbody fusion. Eur Spine J. 2012;21(11):2265-70.

6. Kim HJ, Kang KT, Son J, Lee CK, Chang BS, Jin SY. The influence of facet joint orientation and tropism on the stress at the adjacent segment after lumbar fusion surgery: a biomechanical analysis. Spine J Off J N Am Spine Soc. 2015;15(8):1841-47.

7. Kumar M, Baklanov A, Chopin D. Correlation between sagittal plane changes and adjacent segment degeneration following lumbar spine fusion. Eur Spine J. 2001;10(4):314-9.

8. Zheng Z, Liu H, Sribastav SS, Li Z, Wang J, Yang H. Effect of spino-pelvic sagittal balance on degree of disk degeneration in the lumbar spine. Global Spine J. 2012;2(S 01):43.

9. Schwabegger AH, Wolfram-Raunicher D, Rabensteiner E. Complications, special problems. Congenit Thorac Wall Deform. 2011:277-305.

10. Kim KT, Lee SH, Suk KS, Lee JH, Jeong BO. Biomechanical changes of the lumbar segment after total disc replacement: Charite ${ }^{\circledR}$, Prodisc $^{\circledR}$ and Maverick ${ }^{\circledR}$ using finite element model study. J Korean Neurosurg Soc. 2010;47(6):446-53.

11. Ma J, Jia H, Ma X, Xu W, Yu J, Feng R, et al. Evaluation of the stress distribution change at the adjacent facet joints after lumbar fusion surgery: a biomechanical study. Proc Inst Mech Eng H. 2014;228:665-73.

12. Park P, Foley KT. Minimally invasive transforaminal lumbar interbody fusion with reduction of spondylolisthesis: technique and outcomes after a minimum of 2 years' follow-up. Neurosurg Focus. 2008;25(2):E16.

13. Paul P, Garton HJ, Gala VC, Hoff JT, Mcgillicuddy JE. Adjacent segment disease after lumbar or lumbosacral fusion: review of the literature. Spine. 2004;29(17):1938-44.

14. Chung KJ, Suh SW, Swapnil K, Yang JH, Song HR. Facet joint violation during pedicle screw insertion: a cadaveric study of the adult lumbosacral spine comparing the two pedicle screw insertion techniques. Int Orthop. 2007;31(5):653-6.

15. Park Y, Ha JW, Lee YT, Sung NY. Cranial facet joint violations by percutaneously placed pedicle screws adjacent to a minimally invasive lumbar spinal fusion. Spine J. 2011;11(4):295-302.

16. Park Y, Ha JW, Lee YT, Sung NY. Percutaneous placement of pedicle screws in overweight and obese patients. Spine J. 2011;11(10):919-24.

17. Patel RD, Graziano GP, Vanderhave KL, Patel AA, Gerling MC. Facet violation with the placement of percutaneous pedicle screws. Spine. 2011;36(26):E1749-52.

18. Lau D, Terman SW, Patel R, La Marca F, Park P. Incidence of and risk factors for superior facet violation in minimally invasive versus open pedicle screw placement during transforaminal lumbar interbody fusion: a comparative analysis: clinical article. J Neurosurg Spine. 2013;18(4):356-61.

19. Babu R, Mehta Al, Brown CR, Isaacs RE, Bagley CA, Gottfried ON. Comparison of superior-level facet joint violations during open and percutaneous pedicle screw placement. Neurosurgery. 2012;71(5):S47.

20. Lt H, Jd S, Dp R, Kt F. Minimally invasive transforaminal lumbar interbody fusion: indications, technique, and complications. Am Assoc Neurol Surg. 2006;20(3):1-5.

21. Hy S. Does the facet joint violation by transpedicular screw cause adjacent segment degradation? Presented at the 2011 Annual Meeting of the American Academy of Orthopaedic Surgeons. 2011; Paper 257.(Feb. 15-19. San Diego). 
22. Niosi CA, Wilson DC, Zhu Q, Keynan O, Wilson DR, Oxland TR. The effect of dynamic posterior stabilization on facet joint contact forces: an in vitro investigation. Spine. 2008;33(1):19-26.

23. Hikata T, Kamata M, Furukawa M. Risk factors for adjacent segment disease after posterior lumbar interbody fusion and efficacy of simultaneous decompression surgery for symptomatic adjacent segment disease. J Spinal Disord Tech. 2014;27(2):70-5.

24. Cardoso MJ, Dmitriev AE, Helgeson M, Lehman RA, Kuklo TR, Rosner MK. Does superior-segment facet violation or laminectomy destabilize the adjacent level in lumbar transpedicular fixation?: an in vitro human cadaveric assessment. Spine. 2008;33(26):2868-73.

25. Lau D, Terman SW, Patel R, La MF, Park P. Incidence of and risk factors for superior facet violation in minimally invasive versus open pedicle screw placement during transforaminal lumbar interbody fusion: a comparative analysis. J Neurosurg Spine. 2013;18:356-61.

26. Park Y, Ha JW, Yun TL, Na YS. Cranial facet joint violations by percutaneously placed pedicle screws adjacent to a minimally invasive lumbar spinal fusion. Spine J. 2011;11(4):295-302.
27. Kim M-C, Chung H-T, Cho J-L, Kim D-J, Chung N-S. Factors affecting the accurate placement of percutaneous pedicle screws during minimally invasive transforaminal lumbar interbody fusion. Eur Spine J. 2011;20(10):1635-43.

28. van Schaik JP, Verbiest $H$, van Schaik FD. The orientation of laminae and facet joints in the lower lumbar spine. Spine. 1985;10(1):59-63.

29. Babu R, Park JG, Mehta Al, Shan T, Grossi PM, Brown CR, et al. Comparison of superior level facet joint violations during open and percutaneous pedicle screw placement. Neurosurgery. 2012;71(5):962.

30. Moshirfar A, Jenis LG, Spector LR, Burke PJ, Losina E, Katz JN, et al. Computed tomography evaluation of superior-segment facet-joint violation after pedicle instrumentation of the lumbar spine with a midline surgical approach. Spine. 2006;31(22):2624-9.

\section{Submit your next manuscript to BioMed Central and take full advantage of:}

- Convenient online submission

- Thorough peer review

- No space constraints or color figure charges

- Immediate publication on acceptance

- Inclusion in PubMed, CAS, Scopus and Google Scholar

- Research which is freely available for redistribution

Submit your manuscript at

www.biomedcentral.com/submit

(O) Biomed Central 